\title{
RESENHAS
}

\section{SCHMITT E STRAUSS: UM DIÁLOGO OBLÍQUO}

MEIER, Heinrich. Carl Schmitt \& Leo Strauss. The Hidden Dialogue. Including Strauss's Notes on Schmitt's Concept of the Political \& Three Letters from Strauss to Schmitt. Translated by J. Harvey Lomax. Foreword by Joseph Cropsey. Chicago: The University of Chicago Press, 1995.

\author{
Cássio Corrêa Benjamin* \\ ccbenj@yahoo.com
}

O livro de Meier é sobre as mudanças em um livro ou, mais precisamente, mudanças em sucessivas edições de um livro. O livro em questão é $O$ Conceito do Político de Carl Schmitt, nas edições de 1927, 1932 e 1933 (além da reimpressão da segunda edição em 1963). Meier acompanha as mudanças de forma minuciosa, tentando revelar qual o motivo para que elas tenham ocorrido. E esse motivo residiria fundamentalmente na crítica de Leo Strauss - essa é a tese de Meier. Strauss tinha escrito um texto relativamente curto sobre $O$ Conceito do Político - "Notas sobre O Conceito do Político de Carl Schmitt" - e o enviado a Schmitt. O que Meier tenta mostrar é que mesmo não tendo citado o jovem e ainda desconhecido filósofo, as alterações indicam uma reação a uma crítica, uma espécie de diálogo. Por isso, o subtítulo: o diálogo encoberto.

Por que Strauss se interessa pelo livro de Schmitt? Fundamentalmente, por sua crítica radical ao liberalismo. Entretanto, segundo Strauss, tal crítica ainda permanece no horizonte do próprio liberalismo. Portanto, ao escrever sobre Schmitt, Strauss pretende completar e avançar essa sua crítica. Schmitt quer chegar ao critério, ao que é específico ao político. Sendo assim, o político

* Doutorando em Ciência Política. DCP - UFMG.

KRITERION, Belo Horizonte, nº 118, Dez./2008, p. 443-448. 
estaria inserido na cultura, seria uma das "províncias da cultura". Strauss aponta a ambigüidade da busca de um critério do político, da busca de algo que the seja específico. Para ele, Schmitt não se separaria suficientemente da idéia do político como apenas uma das províncias da cultura. Entretanto, Strauss revela que Schmitt, ao mostrar a possibilidade da guerra e da morte, considera o político como fundamental, e não como um domínio relativamente independente. $\mathrm{O}$ político para Schmitt, então, passa a ser o que tem autoridade.

No segundo capítulo, o A. indica uma mudança relevante no texto da primeira edição de $O$ Conceito do Político. Schmitt inicia sua argumentação na defensiva. Ele está em busca da objetividade e independência da política. Mas a partir da noção de "Estado total", aquele para o qual "tudo é político, pelo menos potencialmente" (p. 22), Schmitt parte para a ofensiva. Em vez de um domínio próprio e independente, agora ele fala de distinções fundamentais e últimas da política. Ocorre uma mudança de uma noção de política baseada em domínios para uma outra baseada em intensidade. Nesse sentido, a política pode surgir de qualquer ponto a abranger todos os eventos. Mas se se trata de intensidade, o A. pergunta: qual é o grau de intensidade que Schmitt considera o ponto extremo do político? O próprio Schmitt responde: "os pontos extremos da grande política são aqueles momentos nos quais o inimigo é percebido com uma clareza concreta como inimigo" (p. 28). Nesses momentos, a própria identidade é estabelecida e ganha uma figuração visível.

Strauss amplia a crítica de Schmitt ao liberalismo e faz com que o próprio Schmitt perceba do que se trata. Trata-se da crítica da filosofia da cultura. Strauss aprofunda sua visão: cultura pressupõe algo que é cultivado, "cultura é sempre cultura da natureza" (p. 31). Ele retoma a questão do status naturalis, a esquecida fundação da cultura. Ocorre, então, para Strauss que o político de Schmitt equivaleria ao status naturalis de Hobbes. Isso significaria dizer que o político de Schmitt seria o status fundamental e extremo do homem.

Quanto às diferenças, Strauss aponta que enquanto em Hobbes o estado de natureza é negado, em Schmitt, trata-se de afirmar o político. Enquanto em Hobbes o Estado pode exigir apenas uma obediência parcial (limitada pelo direito à vida), em Schmitt a unidade política pode exigir que seus membros estejam prontos para a morte. Em Schmitt, trata-se da afirmação do político; em Hobbes, da afirmação da civilização. Por isso, para Strauss, Hobbes é o fundador do liberalismo. O que Strauss faz é mostrar a Schmitt os pressupostos e conseqüências de suas próprias idéias, além de revelar-lhe o seu principal oponente: Hobbes.

Strauss concorda com a crítica de Schmitt e afirma: “o político - o agrupamento da humanidade em amigos e inimigos - deriva sua legitimação 
da seriedade da questão do que é o certo" (p. 42). Entretanto, Strauss situa a questão do que é o certo no âmbito da filosofia política, no âmbito daquilo que é tratado pela razão humana. Segundo o A., Schmitt se coloca em outro plano, o espaço da teologia. Strauss seria um filósofo, Schmitt, um teólogo. É isso o que separa radicalmente Schmitt e Strauss. Para o A., Strauss está certo ao dizer que a afirmação do político em Schmitt é a afirmação da moral. Mas Strauss não perceberia com nitidez que a asserção da moral está baseada, em última instância, no teológico. Segundo o A., ao contrário de asseverar um estado de natureza, Schmitt concebe um estado de historicidade, "um estado de decisão moral exigente".

Interrogando Schmitt a partir da filosofia política, Strauss acaba por pressioná-lo a assumir mais claramente os pressupostos de uma teologia política. Strauss toca no ponto central da argumentação de Schmitt: pode-se demonstrar que o político é inescapável? Segundo Schmitt, toda teoria política legítima pressupõe que o homem é mau - um ser perigoso e dinâmico. O que Strauss argumenta é que tal pressuposto não pode ser provado, não pode ser conhecido, é apenas uma questão de crença. Sendo assim, o político pode não ter fundamento. Contudo, o fundamento do político em Schmitt, para o A., não é uma antropologia, mas a teologia. O ponto central é a noção de pecado original - a base do homem mau e perigoso. Para o A., Schmitt não é um antropólogo, Schmitt é um teólogo, um teólogo político.

A conexão entre política e filosofia se torna visível quando Schmitt ressalta "o único caso que importa" (p. 56): a batalha contra o inimigo providencial. Para o A., "o pecado original é o ponto central em torno do qual tudo gira, em sua confissão antropológica da fé" (p. 57). Por isso, depois de ser alertado por Strauss sobre a necessidade da negação do mal do homem como mal inocente, Schmitt retira de seu texto, na edição de 1933, várias passagens que poderiam dar tal impressão.

Schmitt responde a questão da necessidade do político de várias formas. Em uma delas, ele ressalta a inescapabilidade da política porque as oposições metafísicas são inevitáveis. Strauss também chama a atenção de Schmitt para a sua visão formal da política. Por isso, tal modo de compreender a política seria, no fundo, liberalismo com sinal trocado.

Para o A., o conceito do político oferece mais do que um simples critério. Não se trata aqui - esta é a tese do livro de Meier - de um conceito formal. Não se trata de liberalismo com sinal trocado. Por isso, o A. ressalta que somente na edição de 1933, Schmitt afirma que as guerras santas e as cruzadas da Igreja "podem ser baseadas em uma decisão especialmente genuína e profunda sobre o inimigo" (p. 66). O A. se pergunta por que ele manteve veladas suas intenções 
por tanto tempo, por que ele deu a impressão de ser neutro e, o mais importante, por que ele ocultou seu julgamento moral e sua posição valorativa sobre a política? Finalmente, por que Schmitt dissimulou seus pressupostos teológicos sobre a política? Para o A., primeiramente, porque o liberalismo é justamente aquele inimigo que dissolve a verdade metafísica na discussão. Além disso, o que é mais relevante para a tese do livro, a hipótese do autor é que Schmitt ocultou o fundamento de seu pensamento porque o centro de seu pensamento é a fé. A crítica de Strauss, segundo o A., indicaria algo que é válido para o próprio crítico - Strauss se situa no âmbito da filosofia - e não para o criticado. Os pressupostos de Schmitt, portanto, seriam o pecado original, a revelação e a Providência. A antropologia não teria papel algum aqui.

Para o A., na terceira edição de $O$ Conceito do Político, Schmitt acentua o peso que ele atribui ao liberalismo como o inimigo do político. Schmitt compreende essa nova visão de mundo, expressa tanto pelo liberalismo quanto pelo marxismo, como uma nova fé. Portanto, deve ser combatida no terreno da teologia política. A tese central do A., então, é explicitada mais uma vez: "teologia política é a única descrição apropriada e apta para o ensinamento de Schmitt" (p. 76).

O A. ressalta que Schmitt reforça o papel da teologia política ao acentuar a importância da decisão. Entretanto, a teologia política não pode dizer quando, onde e contra quem a decisão deve ser tomada. Não se pode determinar uma tomada de posição particular ou uma orientação concreta. A decisão é e permanece um problema de fé. Mas, o A. pergunta, a decisão nascida da obediência de fé na suprema autoridade não poderia ser distinta da decisão que se baseia no nada? "No caso de Schmitt, tudo depende da resposta a esta questão" (p. 80).

O caráter teológico da obra de Schmitt explicaria sua noção de katechon ou a autodescrição de Schmitt como Epimetheus cristão. Por isso, segundo o A., Schmitt "procura fazer com que se entenda $O$ Conceito do Político no sentido de uma antecipação de um comando, como a ação de um Epimetheus cristão no estado de historicidade e do Julgamento" (p. 83). Strauss não teria o horizonte da fé em vista, quando cobra de Schmitt ir além do liberalismo. O caminho apontado por Strauss é a crítica ao pressuposto fundamental do presente, a saber, o de que todo pensamento, entendimento e ação são históricos, não têm outro fundamento além da decisão humana sem fundamento. Segundo Strauss, para realizar a crítica ao liberalismo e perceber a importância de Hobbes é necessário, antes de tudo, compreender Sócrates. Seria esse ponto de partida que faria com que o "problema teológico-político" permanecesse o tema central também para Strauss. 
Dois pontos iniciais sobre a argumentação de Meier. O primeiro é sobre sua idéia central da obra de Schmitt. Meier parece pensar que sempre foi clara para Schmitt a estrutura teológico-política de sua obra. Dessa forma, a obra de Schmitt se assemelharia a um contínuo "desvelamento" dessa estrutura teológica. Por isso, a pergunta que Meier faz em relação às críticas de Strauss a Schmitt: "por que Schmitt se esforçou para ocultar os pressupostos teológicos de sua política?" (p. 68). Há uma resposta mais simples e mais adequada: as mudanças nas edições de 1927, 1932 e 1933 não são um processo de "desvelamento", mas uma genuína transformação do pensamento de Schmitt. Mesmo que se conceda que essas modificações ocorram na direção do teológico.

A outra questão é sobre a presença ou ausência de formalismo na noção do político em Schmitt. Em todo o livro, Meier tenta mostrar como Schmitt tem, no fundo, uma visão "material”, não formalista, do político. Schmitt seria levado a expressar claramente essa idéia quando explicita sua resposta à acusação de "liberalismo com sinal trocado", portanto, ainda formal. Finalmente, na terceira edição, Schmitt diz que as guerras santas e as cruzadas da Igreja se baseiam em uma decisão profunda sobre o inimigo. Em suma, agora haveria conteúdo concreto na decisão. Meier, então, faz crescer em evidência várias noções presentes na obra de Schmitt, como o pecado original, o inimigo como ferramenta da Providência, as distinções metafísicas, o katechon, o Epimetheus cristão, etc. Todas essas figuras ganham um sentido preciso na interpretação de Meier, como índices de materialidade do político ou, mais claramente, de conteúdo da distinção amigo/inimigo. O teológico, para Meier, não tem apenas uma função de fundação, mas de fundação e vinculação de conteúdo. O problema é que não está tão evidente esse comprometimento material de Schmitt e é essa uma das principais fontes da crítica de Strauss. Além disso, grande parte do interesse da obra de Schmitt está exatamente em não se tratar somente dos escritos de um teólogo cristão ou, ainda mais, católico. Mesmo se aceitássemos o espaço preeminente do teológico - pensando que ele funda a distinção amigo/inimigo -, mesmo assim, não se tem o conteúdo da distinção. Dessa forma, sem dúvida, o que se evidencia nesse formalismo é um inegável aspecto de modernidade na visão schmittiana. Schmitt parece ser mais moderno do que Meier estaria disposto a conceder.

Dois pontos finais sobre o livro de Meier. Essa obra ganhou destaque devido ao fato de evidenciar o aspecto propriamente teológico-político do pensamento de Schmitt. Ao colocar como o centro do pensamento schmittiano a questão teológica, Meier acaba por abrir vários caminhos novos de leitura. A outra questão relevante se refere à importância do pensamento de Strauss. 
Na verdade, este não é um livro sobre Schmitt somente, mas sobre Schmitt e Strauss. O "diálogo encoberto" lança luz sobre as idéias schmittianas e também sobre Strauss - deve-se ressaltar a atividade de Meier como editor das obras completas de Strauss na Alemanha, além de ter publicado um livro sobre seu pensamento. Embora Meier se limite às últimas páginas do livro em seu comentário sobre a obra de Strauss, é inegável a ambição de interpretação da obra como um todo. E se, no fundo, se trata do debate entre uma teologia política e uma filosofia política, o que Meier quer mostrar é a inserção de Strauss também na questão teológico-política. Embora ressalte as diferenças, as fronteiras entre os dois âmbitos nem sempre são muito nítidas.

Por fim, deve-se destacar o conteúdo do livro. Além do texto de Meier, constam também o texto fundamental de Strauss, "Notas sobre $O$ Conceito do Político de Carl Schmitt", três cartas de Strauss para Schmitt, bastante reveladoras da relação entre os dois, assim como duas notas: uma sobre as cartas e outra sobre a tradução. É de fato uma edição exemplar. 